\title{
Earnings Losses Through Unemployment and Unemployment Duration
}

\author{
David Wiczer, Economist
}

W

orkers who lose their job face a variety of hardships while unemployed. But beyond the direct cost of job loss, its associated income loss, workers will tend to make less in their next job as well. This is perhaps not surprising intuitively and is certainly expected by economic theory. Coming from unemployment, a worker is not in a good position to select their optimal job nor to bargain for high wages once they find a job. In addition, unemployment may signal-rightfully or not-that a worker was separated for a reason and is less productive than their prior wage required. By either of these stories, unemployment duration should exacerbate the earnings losses. A worker unemployed longer will be more desperate to take a bad job that comes along and have an even worse bargaining position in it. Long unemployment durations also may signal failed attempts to find employment and be an even worse signal than a relatively short unemployment spell. A longer search time, however, may help the worker find a better match and a higher wage in re-employment. This article will explore empirically earnings losses across unemployment spells and show that, in general, the longer the unemployment duration, the larger the loss.

\section{The longer the unemployment duration, the larger the loss.}

To jointly measure earnings and unemployment spells, I use the Survey of Income and Program Participation (SIPP) from 1996 to 2012. This is a unique dataset because it is a high-frequency panel, meaning that it follows the same people for multiple periods and asks them for information relatively often. The respondents stay in the survey for up to four years and every four months give a monthly account of their earnings and labor-force status. This dataset is a powerful tool because it shows workers' earnings exactly before they enter unemployment, the entire unemployment spell, and the wage when they emerge re-employed. I also observe a number of worker demographic and economic

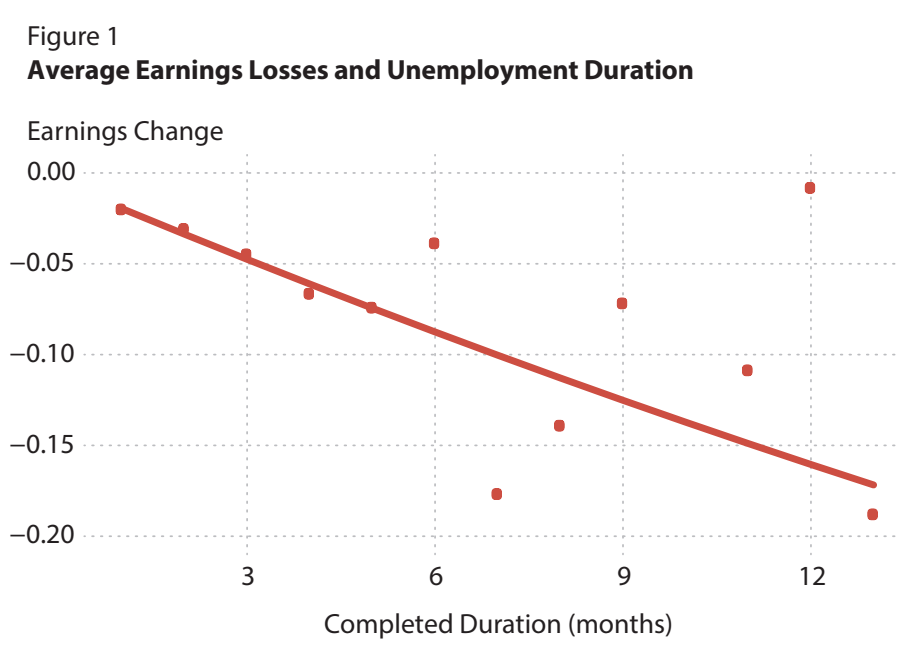

SOURCE: SIPP and author's calculations.

characteristics (age, gender, race, education, and occupation) and control for their average effect on earnings.

To understand the general relationship between unemployment duration and earnings loss, I estimate a cubic function relating earnings before and after an unemployment spell. Figure 1 plots this cubic function along with points that represent the average loss among workers grouped by the number of months unemployed. Notice that the losses grow fairly consistently with unemployment duration. For those unemployed one month, their losses are approximately zero on average. For those unemployed a year, their next job pays about one-sixth less than their previous one.

These losses, however, vary considerably across individuals and groups, so I use a technique called quantile regression to study variation at the individual level. As before, I fit a cubic function to duration, but rather than fitting the average losses for each duration, in Figure 2 I look at how duration affects earnings loss among the biggest losers and gainers - those in the 10th and 90th percentiles (outer shaded area) and the 25th and 75th percentiles (inner shaded area). I also look at the median of earnings loss (middle line), which closely resembles the mean loss from 


\section{Figure 2 \\ Distribution of Earnings Losses and Unemployment Duration}

Earnings Loss

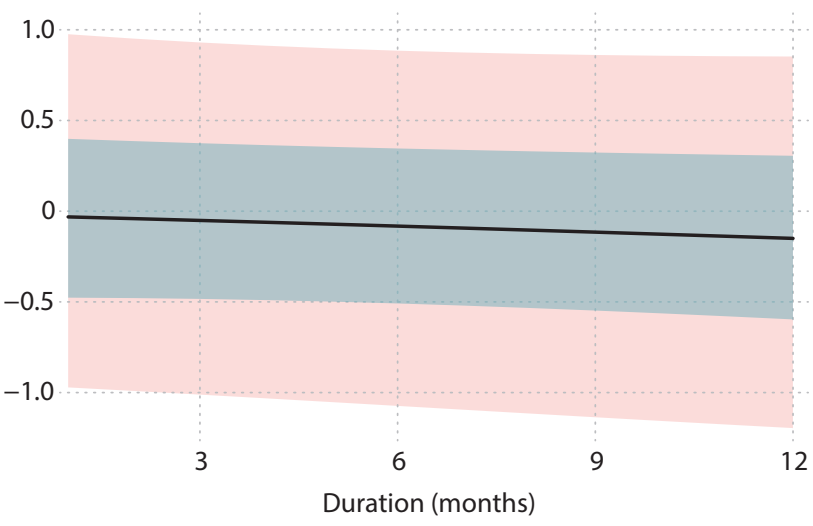

10th to 90th Percentiles

SOURCE: SIPP and author's calculations.

Figure 1. But the dispersion is significant: Those unemployed one month have an interquartile range of about 85 percentage points, slightly skewed negative. At one year, the gap has widened a bit, to about 90 percentage points.

One could break down this distribution of earnings losses a number of ways, but here I look particularly at how much losses vary across initial occupation. Now, I average losses within the occupation from which the workers separate, as if there is a representative unemployed person from among production workers, another from the healthcare support occupations, and so on for each occupation. ${ }^{1}$ Figure 3 again plots the median, interquartile range, and 90-10 range but includes only the average earnings loss within each occupation and then weights these occupations by the fraction who enter unemployment. For those unemployed one month, the interquartile range is about 4 percentage points. At one year, it spreads out quite a bit, to about 16 percentage points. Though the spread across people remains quite consistent throughout their unemployment duration (see Figure 2), the differences are increasingly pronounced across occupations.
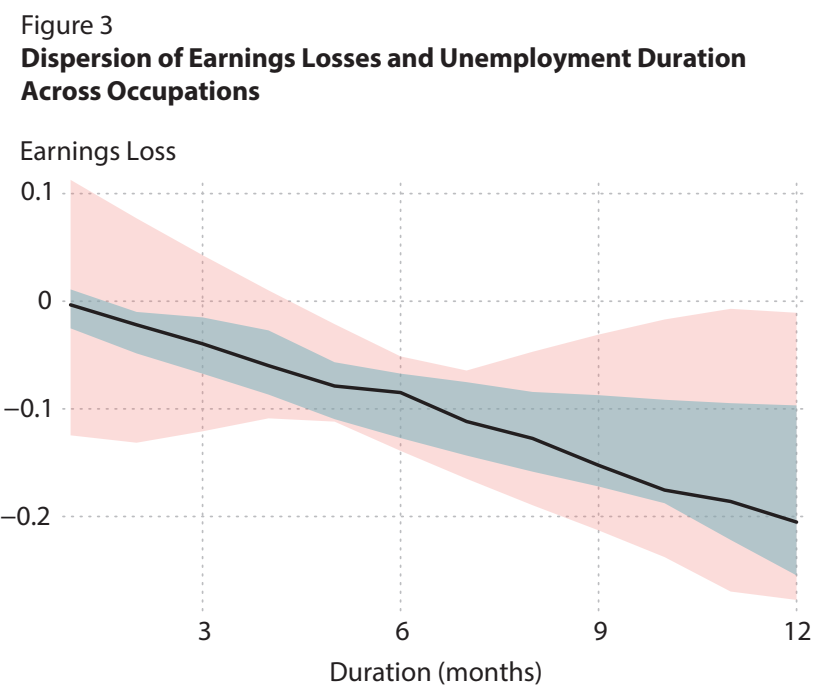

10th to 90th Percentiles

25th to 75 th Percentiles

SOURCE: SIPP and author's calculations.

\author{
Note \\ 1 The list of occupations is available at \\ https://www.bls.gov/soc/socguide.htm\#LINK2.
}

